\title{
BMJ Open Healthy Canadian adolescents' perspectives of cancer using metaphors: a qualitative study
}

\author{
Roberta Lynn Woodgate, David Shiyokha Busolo
}

To cite: Woodgate RL, Busolo DS. Healthy Canadian adolescents' perspectives of cancer using metaphors: a qualitative study. BMJ Open 2017:7:e013958.

doi:10.1136/bmjopen-2016013958

- Prepublication history for this paper is available online. To view these files please visit the journal online (http://dx.doi.org/10.1136/ bmjopen-2016-013958).

Received 20 August 2016 Revised 5 November 2016 Accepted 6 January 2017

\section{ABSTRACT}

Objectives: Cancer has been described using metaphors for over 4 decades. However, little is known about healthy adolescents' perspectives of cancer using metaphors. This paper reports on findings specific to adolescents' perspectives of cancer using metaphors. The findings emerged from a qualitative ethnographic study that sought to understand Canadian adolescents' conceptualisation of cancer and cancer prevention.

Design: To arrive at a detailed description, data were obtained using individual interviews, focus groups and photovoice.

Setting: 6 high schools from a western Canada province.

Participants: 75 Canadian adolescents.

Results: Use of 4 metaphors emerged from the data: loss (cancer as the sick patient and cancer as death itself); military (cancer as a battle); living thing (haywire cells and other living things) and faith (cancer as God's will) metaphors, with the loss and military metaphors being the ones most frequently used by adolescents. Adolescents' descriptions of cancer were partly informed by their experiences with family members with cancer but also what occurs in their social worlds including mass media. Adolescents related cancer to emotions such as sadness and fear. Accordingly, more holistic and factual cancer descriptions, education and psychosocial support are needed to direct cancer messaging and clinical practice.

Conclusions: Findings from this study suggest that the public and healthcare providers be more aware of how they communicate cancer messages.

CrossMark

Rady Faculty of Health Sciences, College of Nursing, University of Manitoba, Winnipeg, Manitoba, Canada

Correspondence to Dr Roberta Lynn Woodgate; Roberta.Woodgate@ umanitoba.ca

\section{INTRODUCTION}

Cancer is a complex and emotionally fraught disease that is often described using metaphors. ${ }^{1}{ }^{2}$ Cancer description using metaphors has often been from the perspectives of adults ${ }^{3}$ and healthcare providers ${ }^{1}$ with little attention given to adolescents' perspectives. In this regard, this paper presents Canadian adolescents' perspectives of cancer using metaphors.

\section{Strengths and limitations of this study}

- To the best of our knowledge, this study is the first of its kind in Canada to examine adolescents' perspectives of cancer using metaphors.

- The large number of adolescent participants $(\mathrm{N}=75)$ from six different high schools presents foundational knowledge specific to Canadian adolescents' perspectives of cancer and adds to the growing body of knowledge on adolescents' lay understanding of cancer.

- We used robust research methods of openended individual interviews, photovoice and focus group discussions to generate our important findings.

- Limitations in the sample included a sample that was primarily female and in the younger and middle age range of adolescence, as well as lacking in ethnic diversity.

- Given the paucity of research involving healthy adolescents' perspectives of cancer using metaphors, discussion on how the findings from this Canadian study relate to adolescents from other countries cannot be made.

\section{Cancer and metaphors}

Metaphor translates from the Greek term metaphera which means 'going beyond' (ref. 5 , p. 1232) and 'to transfer or carry across' (ref. 6, p. 269). Metaphor is a figure of speech whereby a word or phrase literally refers to an object or idea and this word or phrase is used in place of another to suggest similarity between them. ${ }^{2}$ Accordingly, metaphors are often used to provide a lay understanding of a phenomenon. The history of the use and definition of metaphors can be traced back 2400 years when Aristotle described metaphor in his Poetics as 'giving the thing a name that belongs to something else' (ref. 7, p. 1476).

With regard to cancer description, metaphors have been used since the times of Hippocrates (460-370 BC) when cancer was compared with 'long bulky veins radiating from lumps in the breast' and to crabs which 
are called 'carcinoma' in Greek (ref. 8, p. 231). The term 'carcinoma' was later translated into the Latin word 'cancer' by Celsus (who lived around 28-50 BC; ref. 9, p. 9) which has recently been described as the movement of crabs. ${ }^{10}$ Cancer description as movement of crabs is comparable to the 'growing out of control and eating away at the body's organs' (ref. 11, p. 44) and the 'invasive nature' of the disease (ref. 12, p. 714). Moreover, cancer has been described using metaphors like 'consumption' (ref. 9, p. 9) or 'silent killer' (ref. 13, p. 489) that have often been classified as militaristic. 91415 In other ways, cancer has been described using metaphors of journeying, sailing or working, ${ }^{16} 17$ and as sports like ${ }^{1819}$ ecological $^{20}$ or engineering metaphors. ${ }^{21}$

Of the different metaphorical ways that cancer has been described, military metaphors have received considerable attention. ${ }^{9} 1415$ In the 20th century, military metaphors dominated the medical language, especially in relation to cancer. ${ }^{12}{ }^{13}$ War on cancer was popularised in the 1970s through advertisements that initiated fear as a way of generating support for cancer research funding. ${ }^{12} 22$ A famous military reference to cancer was made by the US President Nixon in 1971 where cancer was referred to as a 'battle' or a 'war' to be fought and an illness to be killed (ref. 12, pp. 709, 714). By waging war on cancer, resources were harnessed and protocols bypassed to ensure that the president was involved in cancer control efforts. ${ }^{12}$

When used, military metaphors often describe cancer as an attack on the body. ${ }^{17}$ At other times, they are used to portray medical professionals as commanders who give orders and are allied with each other, while patients are described as the brave and heroic soldiers, with their bodies being the battlefield. ${ }^{20}$ Sometimes the military metaphors are applied to how the body reacts to cancer, where cancer is referred to as the intruder that attacks the body which tries to 'defend' itself (ref. 9, p. 63).

In spite of their extensive use, military metaphors appear to provide insufficient lay understanding of cancer and cancer experience. Consequently, other metaphors have emerged to capture the more holistic approach to cancer that may go beyond fighting to acceptance and healing. ${ }^{12}{ }^{18}$ In this regard, some describe cancer as a sport to capture the happiness of being alive and enjoying the game. ${ }^{18} 19$ The team aspect of the metaphor highlights the involvement of other individuals such as family, friends, neighbours and medical professionals who are part of the patient's life and make the experience a team effort. The team sport metaphor includes the importance of staying in the game, of knowing 'when to call a time-out' and of celebrating 'the small victories' (ref. 18, p. 349).

Similarly, approaching cancer as a journey recognises that different patients with cancer can experience, explore or exit the many routes that living with cancer presents. ${ }^{14} 23$ The metaphor of illness as a journey allows for reflections about the authenticity of life journey, direction, goal and progress. Owing to cancer, patients might have to leave the freeway of life (often travelled at high speed or on 'cruise control') to take a byway that brings uncertainty but also new meaning, strength and possibly personal growth (ref. 23, p. 4026). Thus, this metaphor 'encompasses possibility: for exploration, struggle, hope, discovery and change'(ref. 23, p. 4026). However, the journey takes place during and after cancer treatment, and its route, length, destination and pace are unknown and are subject to spontaneous change. As such, the metaphor of cancer as a journey is quieter than the military metaphor and waives the ideas of winning or losing, or failing. Instead, the metaphor contains various roads and avenues that can be taken and explored. ${ }^{14}{ }^{23}$ In the same way as a grieving process is not always structured and linear, a cancer journey is not linear but often a process that is cyclical, and can evolve over time. ${ }^{16}$ As such, the metaphor of cancer as a journey has been complemented with the image of a compass, something that gives direction, that helps us to find our way and that helps 'make the unseen more manageable' (ref. 16, p. 945).

Annas $^{20}$ suggests using ecological metaphors that employ words like conservation, balance, diversity and sustainability which could help realise that resources and expectations are limitless. For Van Rijn-van Tongeren, ${ }^{21}$ cancer can be described using an engineering metaphor where cancer is likened to a machine, something that is dehumanised and that can be controlled.

\section{Metaphor use by individuals with and without cancer}

Metaphors have been used by individuals with cancer. $^{1}{ }^{3} 4$ 24-26 Individuals with cancer use metaphors to describe themselves and their cancer, and to express their experiences in ways that are meaningful to them. For example, in one study, adolescents and young adults with cancer used online social networking groups to talk about themselves, the cancer affecting them, and experiences of living with cancer by using metaphors like 'growth' and 'seedlings'. ${ }^{26}$ Healthcare providers also use metaphors to help promote understanding of cancer and its treatment by patients with cancer. For instance, Subbiah $^{24}$ described using metaphors derived from the movie 'Zombie land' to help an adolescent patient understand cancer treatment and provide consent for surgery. In contrast, there is less work describing the use of metaphor by individuals without cancer. In the sections that follow, we take a closer look at some of the aforementioned studies on how individuals with and without cancer described cancer using metaphors.

\section{Adult cancer}

Literature on cancer description using metaphors has mainly focused on adults, especially those diagnosed with cancer. ${ }^{134}$ In one study, the use of metaphor in cancer conversations between 52 oncologists and their patients, who were between ages 28 and 86 years, was analysed. ${ }^{1}$ Ninety-four patients had an advanced stage of the cancer, and occurrence of their death was imminent. 
The study included a total of 398 conversations between a physician and one patient with an average of 2-4 conversations between them. Conversations were recorded, and the physicians' parts were coded for figurative language to filter out metaphors. Commonly used metaphors were categorised into sports, militaristic, mechanical or agricultural groups. ${ }^{1}$ Generally, it was less troublesome for patients to understand physicians who used more metaphors.

In another study, investigators analysed whether women with breast cancer had mental images of their illness. $^{3}$ The qualitative study involved 15 participants between ages 39 and 82, excluding 1 participant who did not mention her age. These participants who were from a university hospital in Scotland took part in in-depth interviews and used a toolkit of art material to express mental images of their illness through creation and narration. Fourteen women had a mental image of their cancer, and 12 women were able to create their images with the help of the toolkit. From their depictions, investigators found that women conceptualised cancer based on its colour, shape, size, consistency and texture. ${ }^{3}$ In their pictures, women referred to cancer metaphorically as volcano or jellyfish, which conveyed the appearance, behaviour and intent of the disease. Furthermore, the women's visual images described cancer as a creature. ${ }^{3}$ Participants depicted the illness as independent and not part of their body, but could 'grow, move, feed, hide or spread' (ref. 3, p. 342).

\section{Healthy children and adolescents' perception of cancer}

When it comes to children and adolescents' descriptions, research in this area is still emerging. In a UK-based study, predominantly healthy children and adolescents' knowledge of cancer and their understanding of healthy and unhealthy behaviour were examined. ${ }^{27} \mathrm{~A}$ questionnaire was distributed to 226 urban and rural school adolescents aged 15-16 years, while 100 children between ages 9 and 10 years were interviewed and asked to draw. ${ }^{27}$ Findings revealed that $42 \%$ of the 15-16 years old assumed cancer to be a major reason for adult death, while $14 \%$ assumed the illness to be responsible for young people's death. Among the 9-10 years old, 46 children assumed that cancer can be lethal. The children's drawings revealed four main themes: 'fires in the body', 'specific parts of the body affected, often involving loss of hair', cancer as 'a group of cells', and cancer 'in the form of unpleasant faces or monsters' (ref. 27, p. 1032). From study findings, it was evident that metaphors of death, contagion and blame concealed the accurate conceptualisation of cancer. ${ }^{27}$

As part of a larger study, 195 Scottish children's understanding of cancer was analysed. ${ }^{28}$ Eight to 11 years old children from affluent, rural and deprived backgrounds who attended five different schools took part. The children were asked to draw and write what they knew about cancer. They were also asked to write down and draw what keeps them healthy and what affects their health negatively. Study findings revealed that in general, children demonstrated a good level of awareness as expressed in their drawings and textual responses. Children described cancer in terms of what it is, whereby they described it using metaphors like 'lumps', or 'balls of gas' (ref. 28, p. 292). Cancer was seen in very negative terms by the children at a very early age (even without personal experience; ref. 28, p. 298).

In an Australian study, discursive constructions of cancer by healthy adolescents were examined. ${ }^{29}$ Researchers examined how language, metaphors and performances were used to represent young people with cancer. Adolescents between ages 12 and 18 years from three high school drama classes were involved in creative activities and focus group discussions. The adolescents were invited to imagine the life of a young person of their age with cancer and present their thoughts through creative activities. After 12 creative performances, the adolescents were engaged in focus group discussions where they explored their representations. Through Foucauldian discourse analysis, it was found that adolescents made constructions of youth cancer as an inevitable decline towards death and as overwhelming one's personhood to the point of reducing the adolescent with cancer to a 'cancer victim'. In regard to metaphorical descriptions, the adolescents described cancer bodies as 'thin', 'pale' and 'fragile' (ref. 29, p. 430). They described cancer as a 'doomed thing' that could leave the affected young person 'completely broken' (ref. 29, p. 430). Furthermore, the adolescents appeared to constantly refer to battle metaphors such as 'fighting' in their performances (ref. 29, p. 431).

While findings from these studies are of value, work describing adolescents' use of metaphors in the context of cancer is still wanting. The aforementioned literature reveals that adolescents' description of cancer using metaphors has been limited. Adolescents have described cancer using military, death, blame or contagion metaphors which do not provide an accurate description of the disease. Little is known about how healthy adolescents' description of cancer using metaphors affect their emotions, relationship with people with the illness and engagement in preventive actions. Understanding healthy adolescents' description can be useful in informing effective cancer messages. Since 1995, when the study by Oakley $e t a l^{27}$ was conducted, progress has been made in cancer prevention with healthy youth changing their perspectives of cancer risk factors. ${ }^{30}$ Advancement in research has resulted in more breakthroughs in cancer treatment outcomes and more suggestions have been made at moving away from describing cancer using military metaphors because they can have detrimental effects on cancer prevention and experiences of people with cancer. ${ }^{15} 3132$ To arrive at healthy adolescents' description, qualitative research is needed that will afford them the opportunity to describe cancer in ways that are significant to them. 


\section{METHODS}

\section{Study design}

The findings presented in this paper are part of a qualitative ethnographic study that sought to understand Canadian adolescents' conceptualisation of cancer and cancer prevention. ${ }^{30}$ An ethnographic approach helped to ensure a richness of data as adolescents were afforded the opportunity to present their authentic conceptualisations of cancer using their own language that was meaningful to their culture and social relations. ${ }^{33}$

\section{Participants and procedures}

Participants in this study were adolescents living in Western Canada. In an attempt to achieve variation among adolescents (ie, in age, gender, urban vs rural residence, ethnicity and cancer experience), purposive sampling was used. Adolescents were recruited from six schools in a rural and urban setting. Invitation letters informing adolescents and their parents of the study were sent to their families' homes. All interested adolescents were asked to contact the research team for additional information about the study. Recruitment continued until theoretical saturation was achieved. Parental consent and assent from all adolescent participants was secured prior to data collection.

\section{Data collection}

Data were generated via individual open-ended interviews, the photovoice method and focus group interviews. The process of data collection took place at the preferred location (eg, home, school) of the adolescents and was facilitated by trained research assistants who worked under the supervision of RLW. RLW is a professor with extensive experience in qualitative research and arts-based methods including photovoice. DSB is a doctoral candidate with training in qualitative research. No relationship between the research team and participants had been established prior to the start of the study. This length of time was necessary because we used multiple data collection methods. Data collection had to be suspended intermittently because of school breaks, event schedules and to allow us to arrive at theoretical saturation of the data.

Participants were requested to take part in two individual open-ended interviews. In the initial interview, adolescents were asked to describe cancer and cancer prevention. An interview guide with open-ended questions (eg, How do people get cancer? When you hear the word 'cancer', what does it make you think of?) was developed to facilitate adolescents' sharing of their thoughts, feelings and beliefs about the phenomenon under study. Numerous revisions $(\times 6)$ of the interview guide took place before testing it. After completing the first interview, all adolescents were asked to take part in the photovoice method. ${ }^{34}{ }^{35}$ Adolescents were provided with a disposable camera and asked to take pictures of people (with their permission), places, objects or events that made them think of cancer and cancer prevention.
After adolescents were given a period of 3-5 weeks to take pictures, they were then asked to participate in a second individual interview. Of the 75 adolescents, 53 $(71 \%)$ took part in the photovoice method and second interview. The remaining 22 youth $(29 \%)$ did not participate in the photovoice method and second interview due to other commitments.

During the second interview, the 53 adolescents shared 557 photos with the research team. Use of the photovoice method afforded adolescents a creative and meaningful way to express their understanding and personal meanings of cancer. $^{34} 35$ Photovoice provided them an opportunity to have a dialogue with themselves by reflecting on how they wanted to represent their own perspectives and experiences. ${ }^{36}$ By means of the SHOWeD method, adolescents were asked to describe every picture, what they saw in the pictures, what was happening and what the pictures meant to them, particularly in relation to cancer. ${ }^{37}$ In addition, adolescents were asked to describe why things were happening in the pictures the way they did, if anything could be done about what was taking place and how the pictures could be used to educate others. ${ }^{37}$ Adolescents were also asked follow-up questions that emerged from their first interviews and asked them to comment on emerging themes.

After the second interviews, we planned to conduct four focus group interviews to supplement and confirm the emerging themes on cancer and cancer prevention. ${ }^{38-40}$ A number of adolescents who took part in the individual interviews were invited to take part in the focus groups. Each focus group comprised 3-4 adolescents for a total of 14 youth. Field notes were recorded during the individual interviews and focus groups sessions. Each individual and focus group interview lasted between 60 and $90 \mathrm{~min}$, which were digitally recorded, and later transcribed verbatim.

\section{Data analysis}

Data analysis took place concurrently with data collection and was conducted by both authors. All data emerging from the interviews, photos and field notes were used to inform data analysis specific to themes described in this article. Nvivo V.9.0 was used to organise the data (QSR International Pty. Ltd. Version 9. 2010). In accordance with ethnographic approaches, a multilevel method of analysis was used. ${ }^{41} 42$ The researchers (RLW and DSB) first independently isolated patterns referred to as domains. Domains were then organised by comparing, contrasting and integrating the domains. Attributes were identified for each domain. Finally, relationships among domains were discovered to create themes. The researchers (RLW and DSB) then jointly refined and linked analytic themes and domains.

To ensure a rigorous study, a number of measures were taken including researchers (RLW and DSB) spending a lengthy period of time with the ethnographic data, use of multiple sources of data, careful line by line transcript analysis and detailed memo writing throughout 
the research process. ${ }^{43}$ The choice to discuss initial interpretations with the adolescents themselves during the second and focus group interviews helped to validate emerging themes.

\section{RESULTS}

\section{Participant characteristics}

A total of 75 adolescent participants took part in this study (female: $\mathrm{n}=53,73.3 \%$ ). All adolescents who expressed interest in taking part in the study went ahead and took part. The adolescents ranged in age between 11 and 19 years $($ mean=14.5; $\mathrm{SD}=2.1$ ). Most of the participants (63\%) self-identified as being of European descent with the remaining identifying as other ethnicities (including Asian, African, Jewish, Arabic and Canadian; 19\%), Canadian Aboriginal (11\%) and the remaining $8 \%$ not self-identifying. Among the participants, $31 \%$ either had a family or family friend with a history of cancer. Thirty-three (44\%) adolescents came from rural areas while $42(56 \%)$ resided in urban areas. Adolescents were recruited from junior high or middle (grades 6-8) and high schools (grades 9-12).

\section{Qualitative findings}

The findings revealed that while adolescents demonstrated intelligence and sensitivity in their discussion of cancer and cancer prevention, they nonetheless held misconceptions..$^{30}$ For example, one non-Caucasian adolescent felt sun tanning was not harmful to him because he had brown skin. Although the adolescents obtained their information from cancer education lessons at schools, stories of individuals with cancer and mass media (eg, movies and computer games), they had missing information about certain cancers. Most important of all, it was clear by their discourse that use of metaphors shaped their thinking of cancer. Use of four metaphors emerged from the data: loss (cancer as the sick patient and cancer as death itself); military (cancer as a battle); living thing (haywire cells and other living things) and faith (cancer as God's will) metaphors, with the loss and military metaphors being the ones most frequently used by adolescents. While there were some differences in responses, variation attributable to any of the demographic factors only emerged for the faith metaphor, which was primarily the discourse of adolescents attending schools in the study's rural recruitment sites.

\section{Loss metaphor}

This type of metaphor reflects the losses experienced because of cancer and the psychosocial impact that the loss has on the individual with cancer and his/her family. Adolescents described two types of loss metaphors: cancer as the sick patient and cancer as the grim reaper.

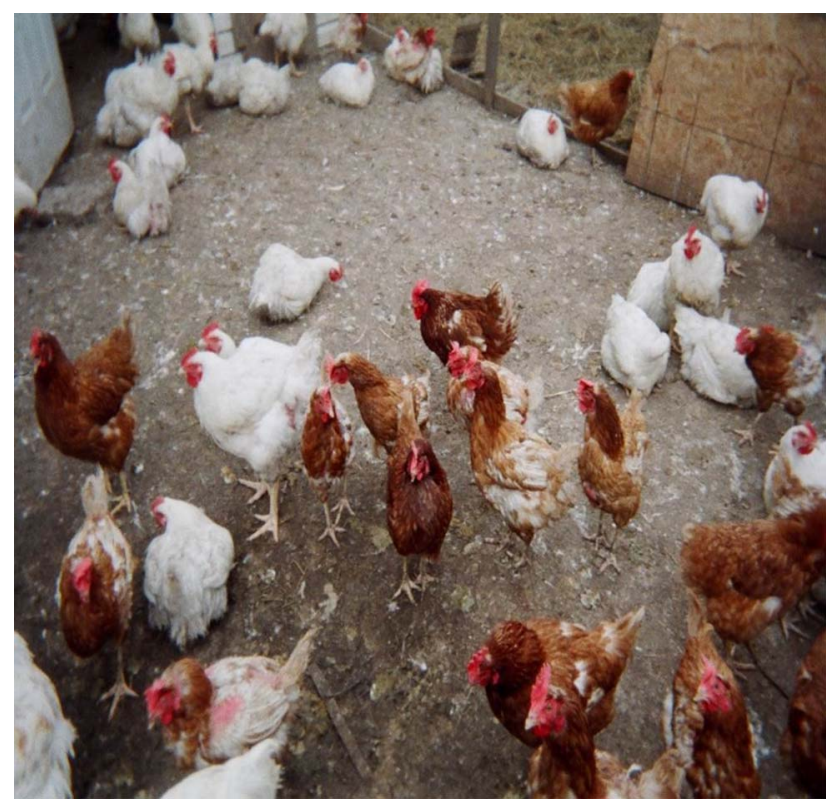

Figure 1 The failing body.

\section{Cancer as the sick patient}

Adolescents equated cancer with the sick patient living in a failing body. The failing body symbolised the deterioration that results from having cancer, in terms of appearance, functional abilities and personhood. Weak, bald (hair), skinny, sick, loss and decay were examples of words used by adolescents in describing the failing body. For example, one adolescent who had a family member with a history of cancer presented a photo (figure 1) of chickens and commented,

I took this picture because the chickens just look sick. Like they look like they have cancer. So, yeah it just reminded me of cancer because when you have cancer you look sick and like you lose hair, so yeah that chicken...It's just always when someone has cancer, I've always seen them like bald. Well it was just kind of strange to see someone that you've known for quite a while without hair...she (family member with cancer) all of a sudden loses her hair and then it's like reality kicks in. (13-year-old girl)

The metaphor of the sick patient with a failing body was also common discourse for those adolescents who never experienced a family member or friend with a history cancer. However, for these adolescents, stories about individuals living with cancer were derived from stories of individuals with cancer as well as from mass media (eg, film, television).

Owing to a deteriorating body and changing personhood, adolescents also viewed the sick patient as a lonely person who had to stay in bed and/or in the hospital, isolated from friends and family and not being free to do the things that he or she would like to do. One adolescent who took a photo (figure 2) that was meant to 


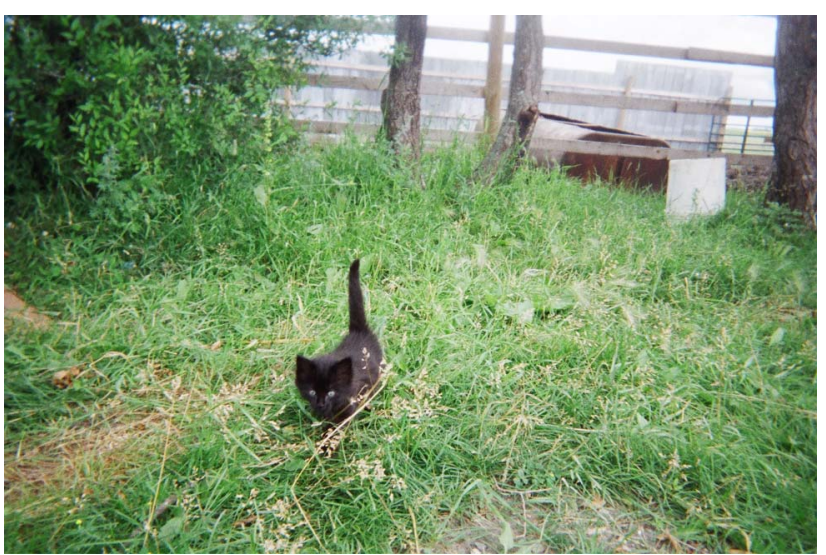

Figure 2 Isolation.

represent the loneliness experienced by the sick patient with cancer expressed,

In the previous photo, I got my brothers and sisters playing soccer, while my sister pretending to have cancer like in the background cause most cancer people they're kind of ignored and everything. Yeah, some people don't really want to hang out with them cause they think that they can't do what they want to. I guess if you truly have cancer then you have to stay in bed and, and like you can't move or anything like that so you can't play soccer or be active or go outside. You are left-out. And the only friends they have are cats and kittens. (13-year-old girl)

The metaphor of cancer as the sick patient was associated with considerable sadness with adolescents viewing the losses experienced by the sick patient as emotionally painful experiences for the individual with cancer and their family members as these two adolescents expressed,

Well one thing is you spend most of your life in the hospital because you're getting like tests and surgeries and stuff like that. You barely get to see your family because you're in the hospital for like half your life and stuff like that and it's emotionally painful...Like it's sad. (12-year-old girl)

It makes me think of just right away, loss of and sadness and just being let down because I mean it can turn everything right around in a complete 360 degrees. Like, you know like your life and it even affects everyone in your life, people around you, friends or family...I think that's just really sad. (12-year-old girl)

\section{Cancer as death itself}

As reinforced by the following comments expressed by adolescents, cancer was also equated with death (the grim reaper),

When I hear the word cancer, I automatically assume death and just like the cancer ward at a hospital I think. (16-year-old girl)
Well usually when our family hears about someone who has cancer unfortunately it usually does lead to them dying. That's what I've experienced. (17-year-old girl)

When I was in the hospital visiting my grandpa, there's like three floors of people with cancer and it was sad to see it and like mostly all of them were on their deathbeds. (12-year-old girl)

Like the sick patient metaphor, the grim reaper metaphor encompassed sadness and pain, both physical and psychosocial pain. One adolescent expressed,

When I hear the word cancer, I think of a lot of people dying of it in a hospital and pain and surgery and stuff like that...Cancer and pain! (12-year-old girl)

In addition to sadness, the grim reaper metaphor was associated with much fear. Words like scary and scariest were often used by adolescents in the discourse of cancer as a grim reaper. Adolescents viewed cancer as one of the worst diseases to have because unlike other diseases they believed individuals have less chance of surviving cancer and that there is almost no cure for it as reinforced by the following,

Cancer is a very bad disease that you really don't want to get. It affects people's lives. Many people will die from it each year and that they don't really have a full cure for it yet. (12-year-old girl)

$\mathrm{Hmm}$, cancer is one of the worst diseases ever. Like there is so many different kinds, like HIV and AIDS is really bad too, but like they have pills that can help a lot, but with cancer they can't do as much. (14-year-old girl)

Even when adolescents recognised that cancer could be cured, they nonetheless were still fearful that cancer would return and that death was always there as reinforced by the following comment,

Like lots of people will go through it and still live but they always have the fear that it will come back because you never know whether it's fully gone or not. I didn't really know it was that bad and like how incredibly dangerous that like cancer is and how it really can kill you but over time or it can do it quickly. It depends on what happens. (16-year-old boy)

Since cancer was equated with death itself, adolescents in this study expressed worry for themselves as well as for their family and friends being diagnosed with cancer as noted by the following comments,

I'm scared honestly like for my family and for myself and like even my boyfriend as his family has a long list of cancer and it's like you know, what if he gets, what if my family gets it. It's just it's scary to think about. (15-year-old girl) 
My family could get it and that somewhat scares me too and it kind of scares me when I hear it...I could get it and I'm really hoping that they'll figure out a cure so that that way you don't have to worry about it very much anymore cause it's a very widely disease. It's getting worse all the time. (13-year-old girl)

\section{Military metaphor: cancer as a battle}

Another popular metaphor used by adolescents was cancer as a battle. Adolescents described cancer using military terms including kill, attack, fight, fighting, survive, invade, destroy and beat. Cancer was viewed by the adolescents as an enemy or intruder that the body needed to attack.

It's the body attacking itself. Like cancer is some modification in your cells in your body that causes your body not to accept the changed cells and tries to expel it from your body by attacking itself. (16-year-old boy)

In describing cancer as a battle between a police officer (immune system of the body) and prisoners (cancer cells), one adolescent explained that the prisoners (cancer cells) needed to be strong enough to break out of jail and fight the police officer (invade the immune system of the body),

I'm going to use police and jail people as an example because they're good and bad. It is like if the guys would break out of the jail cell and they would be strong enough to just overtake the police officer. They need weapons to control the police officers because...that's how a police officer would react the same way and the officers would just say 'drop the gun and come with us' but then the other prisoner would take the gun and do it to other the police officer and so on...the prisoners then change into the police officers' clothes and then they will just go because they have taken the good cells and use them for themselves. (12-year-old boy)

Adolescents also believed that fighting cancer (the enemy) is easier to do if the body (attacker) is healthy as noted by the following comment of fight,

Your body would probably have an easier time fighting off cancer if you were in a healthy stage of your life. (12-year-old girl)

Adolescents reinforced the importance of building a strong healthy body (strong soldier metaphor) in order to be better prepared to fight the dreaded invading cancer cells and shared photos of factors and activities (eg, exercising and eating fruits and vegetables; figure 3) that contributed to being strong and healthy. One adolescent noted,

Like not eating healthy can break down your immune system which in the end if you were to get cancer then it'd be harder to fight off the cancer...Eating healthy is just one small thing that if you were to get cancer, it

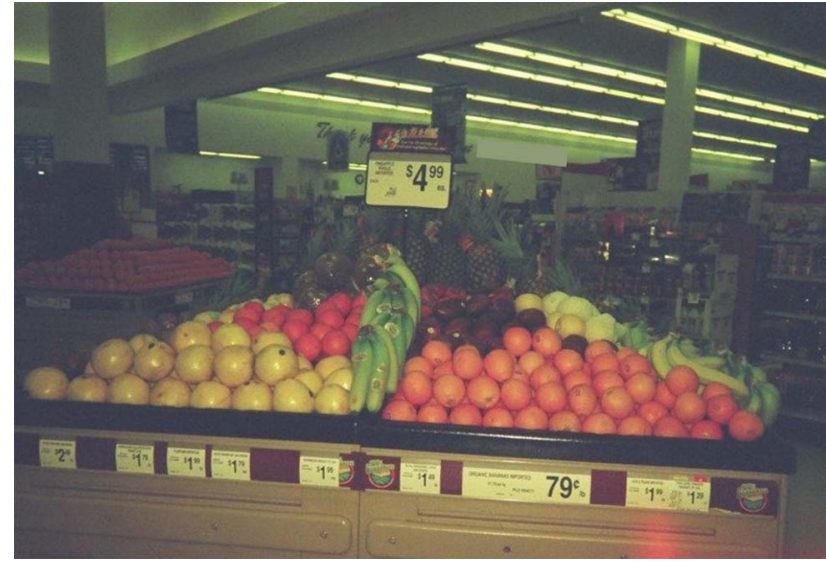

Figure 3 Preparing the soldier.

could help you fight it off...better chance of surviving. (13-year-old girl)

As is the case with war, adolescents talked about the importance of fighting hard and not giving up the fight against cancer. One 15-year-old adolescent used her experience with martial art to reinforce the importance of not giving up when faced with cancer or any other difficult life challenge,

Martial art teaches that you should be respectful and try hard at things. Like if you're working on something don't give up. You should keep trying. Like if something is hard and then I keep working at it and I get then I'm happy and I feel more confident I tried at something and I succeeded.

In another example, one 16-year-old adolescent discussed how her experience as a volunteer at breast cancer run fundraiser events (eg, cancer run) was the result of knowing people with personal connections and found such events to be encouraging as they show the capacity of people to fight back against cancer.

However, adolescents acknowledged that not all will win the cancer battle as reinforced by the following comment,

But lots of people have cancer and that people can fight, but sometimes it's fatal. (13-year-old girl)

Overall, adolescents noted that they became familiar with the military metaphor through messages in the mass media (eg, movies and computer games) as well as how others talked about cancer.

like it's when you have to have the movies are based on the good people a good start and then the bad people come and bring them down and then and always the good people win but cancer that movie wouldn't the good people wouldn't win and cancer would win after that. (12-year-old boy) 
Cancer as a living thing metaphor: big clumps and other living things

When using this type of metaphor, adolescents viewed cancer as something alive, existing as its own being with the ability to grow and spread. While this type of metaphor was used by all adolescents, it was not referenced as frequently as the first two types of metaphors. Examples of living things that adolescents used include animals (eg, bear), virus, creature, monster, weeds and organism. One adolescent provided the example of cancer as a plant and treatment as a fishy.

The cancer can be the plant and the fish could be the chemo eating away the plants. Then like it goes back to the surgery concept, I guess if you get rid of all of it, it's like if the fish eats all of the plants and like, like removes the plant by its roots... but if the fish doesn't eat all of it and then it leaves it huh I guess it could spread again. (13-year-old girl)

Another interesting example of a living thing was the view that cancer existed as big clumps. The big clumps represented the uncontrollable and erratic nature of cancer. Adolescents described cancer as irregular and fast growing cells that transform as they replicate. The mental images of cancer as the big clumps helped adolescents make sense of the process of metastasis.

Cause when cells reproduce too much then it's like clumps and they are big clumps...And that's what cancer is. (13-year-old girl)

Probably it'd be like splits and then like that ball that split it would split and then it'd be bigger and bigger and bigger and spread. (12-year-old girl)

Adolescents noted that cancer cells grow fast and also live longer than normal cells as noted by the following,

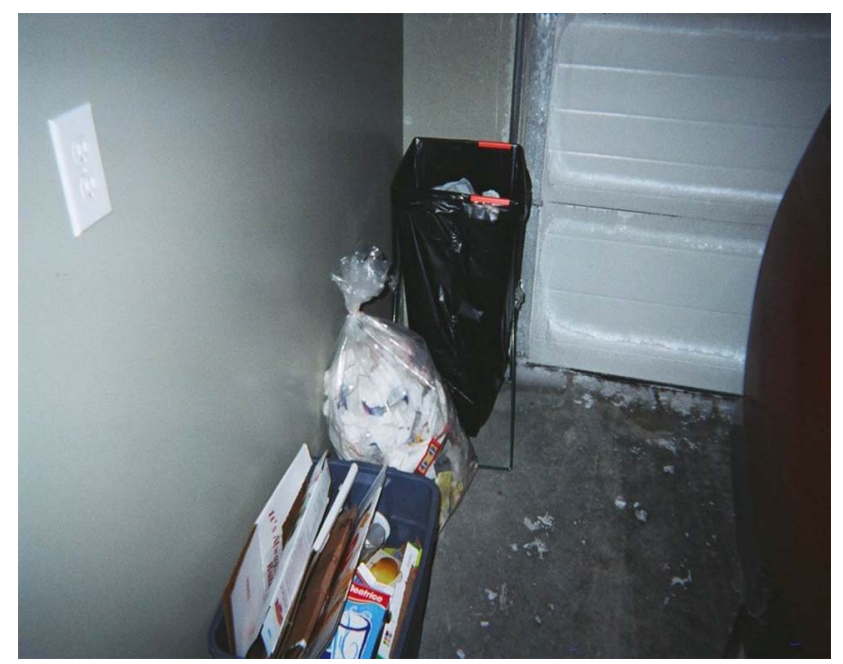

Figure 4 Polluting cells.
I know cells have an age and that they die. But the cancerous ones don't and they just keep um living and living and then they multiply and I think that's how a tumour starts. (17-year-old girl)

In addition to terms like repopulate and mutate, adolescents also used terms that emphasised the polluting nature of the big clumps (eg, decay, debris). In describing her photo (figure 4), one adolescent expressed,

I took a picture of garbage cause cancer is caused by cells that reproduce ineffectively and then multiply uncontrollably and they start taking over your body... disgusting!

\section{Faith metaphor: cancer as God's will}

The metaphor, cancer as God's will, helped adolescents to make sense of cancer through their religious beliefs and understandings. Unlike the other metaphors, this metaphor was primarily shared by adolescents living in the rural recruitment site. The rural area had strong religious roots. Adolescents supporting this metaphor held the belief that everything that transpires in one's life, including cancer, is part of God's will or plan as reinforced by the following,

Like if you can be perfectly healthy, but then just get cancer I guess it's like God's plan for you...Like God has a plan for everybody and he might have the plan for you to get cancer and you have to really trust him when you have it. (14-year-old girl)

One of the adolescents whose sister was diagnosed with cancer believed that God would take care of everything and reinforced that it was important to have faith in God and trust God,

She was pretty sad. I felt sorry for her, but in time she realized it was all the Lord's doing and, and he'll take care of her. (13-year-old girl)

Another adolescent expressed,

It's nice there because we pray a lot at our church and then we can sing there a lot. The most powerful thing you can do is pray for it and that cancer will go away. (12-year-old boy)

But our biggest prevention of cancer is just praying and trusting that God will...He didn't exactly make it happen. He just allowed it to happen for a reason. (13-year-old girl)

Adolescents also held the belief that being diagnosed with cancer brings you closer to God.

Um, probably when the Lord wants them to get it cause some people might get it when they are very healthy, but they don't really believe in the Lord or anything like that so the Lord gives it to them so they'll come closer to him or it's just their time to go. (15-year-old girl) 
Viewing cancer as God's punishment varied among the adolescents who relied on the God's will metaphor. For example, one adolescent expressed,

And our religion says it's our fault if we get sick and our God says we have to watch out like we don't damage your body if you don't have to. Like you don't damage the body for fun. It's like ruining what God made us and it's like ruining him. (14-year-old boy)

In contrast, another adolescent who took a photo of a cross (figure 5) noted,

Well like my whole family we're all Christians and a lot of people say that cancer is a punishment from God. But I don't really take it as a punishment...I don't have a complete answer, but I know for a fact that it's not a punishment, that God loves us very much and that we just need to keep trusting in him. I know a lot of people that got cancer, and they actually become Christians just through having cancer. (13-year-old girl)

\section{DISCUSSION}

This study explored adolescents' understanding of cancer where metaphors were very prominent in the cancer discourse. Adolescents in our study described

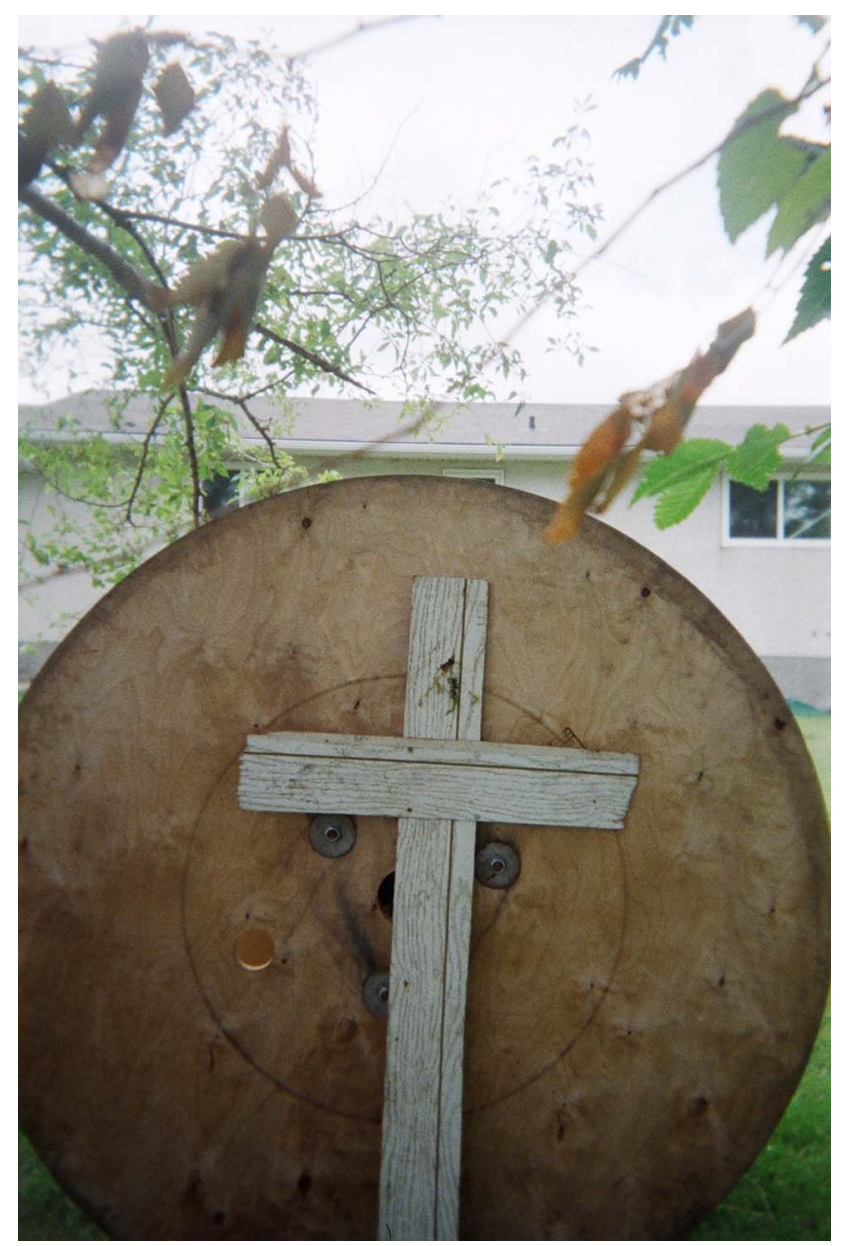

Figure 5 God's will. cancer using metaphors that are similar to those used by adult patients and healthcare providers elsewhere. ${ }^{1}{ }^{3}$ They described cancer using the loss (cancer as the sick patient and cancer as death itself), military (cancer as a battle), living thing (haywire cells and other living things) and faith (cancer as God's will) metaphors, the most dominant ones being the loss and military metaphors.

Description of cancer as a metaphor is said to be deeply grounded in individuals' experiences with the illness. ${ }^{27}$ In the UK-based study, children had more information about cancer when someone they knew had the illness. ${ }^{27}$ In contrast, although adolescents in our study described cancer in similar ways that children in the UK-based study did, most of them (69\%) did not know someone with cancer.

Cancer as the sick patient and grim reaper (loss metaphor) reinforced adolescents' views that cancer is a very isolating and emotionally painful disease. The metaphor constructed by adolescents and associated feelings of sadness or fears have the potential to impact adolescents in two ways. First, they may affect how they cope with a family member's or friend's cancer diagnosis. Adolescents may respond with a sense of hopelessness, fear and uncertainty even in the best of prognoses. Second, describing cancer with loss images that initiate emotions like fear can negatively affect adolescents' help-seeking behaviours such as cancer screening and early diagnosis. $^{31} 4546$

Reference to cancer as the sick patient emphasised adolescents' equation of cancer to the loss of one's personhood. Participants in our study expressed views on how cancer could overwhelm someone's personhood. Cancer could make a person weak, lose his or her hair, be lonely, isolated from friends and family and generally fail to do things that he or she would normally do. In describing cancer, one of the adolescents in our study who had a family member with a history of cancer shared a picture of chickens which she described as sicklooking and bald. Similarly, in an Australian study, healthy young people expressed their construction of cancer in youth as a disease that could diminish one's personhood by reducing the individual with cancer to a 'cancer victim' (ref. 29, p. 432). In spite of healthy adolescents' equation of cancer to loss of one's personhood, youth who have had cancer often perceive themselves as the same people who have perhaps become more mature or experienced personal growth as a result of their experience with cancer. As such, they usually prefer to be regarded as the same person. ${ }^{47}{ }^{48}$ Given this understanding, it is important to educate healthy adolescents on approaching youth who have experienced cancer as the same persons. Additionally, we need to avoid designating people as survivors or victims. ${ }^{49} \mathrm{We}$ need to recognise them as people with a disease, and strengthen the similarities that people with cancer share. ${ }^{49}$ Additionally, reference to cancer as the grim reaper reinforces the need for more accurate cancer 
messages and communication reinforcing that not all cancer diagnoses end fatally.

The military metaphor (cancer as a battle) was also very common and similar to studies where adolescents were not the focus. ${ }^{10} 1449$ In our study, adolescents frequently used the military metaphor as learnt from their social worlds. Participants described cancer using words that commonly relate to those used in movies or computer games. For instance, they made mention of 'the fight of bad people' (cancer cells) by 'police' (body) for 'breaking out of the prison'. Given that adolescents' description of cancer is partially influenced by their social worlds, it is important to carefully frame adolescents' cancer awareness and prevention messages to offer accurate and complete cancer information. ${ }^{50}$ Such information can be useful in increasing adolescents' understanding of cancer and cancer prevention. Inaccurate information communicated through metaphors that embolden adolescents to fight have the potential to undermine prevention efforts that encourage them to practise self-limitation. ${ }^{31}$ Therefore, the media, healthcare professionals, health educators and society in general should rethink the war metaphor in the context of cancer. They should provide more comprehensive and accurate descriptions.

Adolescents referred to cancer as a living thing (eg, cancer as big clumps) that grows, moves and spreads. These assertions are similar to those made by adult patients $^{3}$ and children ${ }^{27}$ elsewhere and reminiscent of the historical metaphor of cancer as crabs that move. Mental images of cancer as living things helped adolescents to make sense of the process of metastasis.

The final metaphor, the faith metaphor (cancer as God's will), was grounded in the adolescents' religious and spiritual beliefs. The religious and spiritual reference to cancer is well addressed in other cancer articles. ${ }^{51} 52$ Often times, the religious metaphors are used by patients with cancer from minority ethnic populations. ${ }^{52}$ In our study, reference to the faith metaphor was mainly expressed by healthy adolescents from a rural area that has strong religious roots. Therefore, future studies may explore factors affecting choice of religious metaphors among adolescents. Religion and spirituality are important factors that help people cope with cancer. ${ }^{53}$ People with cancer who consider themselves as religious or spiritual usually have less anxiety and distress than those who do not consider themselves that way. ${ }^{53}$ Therefore, adolescents' belief that one can get cancer as a punishment from God is a little concerning. These adolescents may blame themselves, or blame people with cancer for damaging their bodies and fail to support them. Further examination of adolescents who perceive cancer as a punishment from God is warranted including examining their health-seeking intentions and behaviours.

\section{Strengths and limitations}

Studies examining cancer as a metaphor among healthy adolescents are only emerging. To the best of our knowledge, this study is the first of its kind in Canada to examine cancer as a metaphor among adolescents. In this regard, this study has generated foundational knowledge specific to adolescents' perspectives of cancer and adds to the growing body of knowledge on adolescents' lay understanding of health and illness. ${ }^{54} 55$ We believe that our robust research methods are one of the strengths towards generating our important findings. Limitations included a sample that was in the younger and middle age range of adolescence with only $17 \%$ of participants being 17 years and older. The sample was also primarily female $(72 \%)$. Fewer adolescents who were older and male may explain why no age or gender differences were uncovered. Likewise, in spite of striving for a diverse sample, we were unable to obtain diversity in ethnic backgrounds. Future studies that account for limitations in the study's sample are warranted as it might result in additional perspectives on adolescents' lay understanding of cancer. Additionally, a closer examination of how having a family or family friend with a history of cancer shapes adolescents' use of metaphors is further warranted considering that the loss metaphor was a common discourse for all adolescents including those who never experienced a family member or friend with a history of cancer.

\section{Implication for clinicians, policymakers and future research}

The findings from this study reinforce that we need to reconsider how metaphors are used. ${ }^{15} 3256$ Healthcare professionals need to be careful about their choice of metaphors in cancer communication with adolescents of families experiencing cancer. Before choosing the type of metaphor to use, healthcare professionals should assess how adolescents view cancer. Holistic and factual cancer descriptions, education and psychosocial support are needed to direct cancer communication and clinical practice. More realistic metaphors based on adolescents' choices need to be used to convey more realistic understanding of cancer.

Some investigators suggest that when using metaphors, one needs to balance information with regard to what is accurate and what is wanted without creating undue anxiety. ${ }^{27}$ Similarly, authors of a Scottish study noted the need to demystify cancer by using every opportunity to present cancer using positive images and describing its treatment and chances of survival. ${ }^{28}$ They stress the importance of taking into consideration different cultural and socioeconomic contexts in cancer descriptions. ${ }^{28}$ Education on the psychosocial aspects of cancer is needed to extend adolescents' knowledge beyond the physical nature of cancer to address their fear, sadness and misconceptions. Unlike studies reporting on adolescents elsewhere, ${ }^{45}{ }^{57}$ Canadian adolescents in this study were fairly informed about cancer. Nonetheless, more needs to be done in educating adolescents about cancer as indicated by some of their discourse related around metaphors. 
Given the paucity of research involving adolescents' description of cancer using metaphors, an discussion on how the findings from this Canadian study relate to adolescents from other countries is limited. Importantly, research with adolescents from different populations needs to be conducted. Future research is also needed to examine the long-term impact of adolescents' description of cancer using metaphors on their engagement in preventive behaviour.

\section{CONCLUSION}

Findings from this study clearly indicated that adolescents go beyond the general knowledge and description of cancer and use metaphors to make sense of cancer. Czechmeister $^{5}$ described metaphors as 'two-edged swords' that are essential to individual and collective expression, but may have negative consequences, creating confusion, fear, stereotype and stigma (p. 1226). The metaphor as a 'two-edged sword' (ref. 5, p. 1226) held true for the adolescents in this study-use of metaphors helped adolescents make sense of cancer yet at the same time reinforced the fear, sadness and confusion they associate with cancer. Therefore, education that appropriately describes cancer in its wholeness is needed to better inform adolescents' lay conceptualisation of cancer.

Acknowledgements The authors thank all the youth who took part in this study and the research assistants who collected data under the supervision of the first author.

\section{Twitter Follow Roberta L Woodgate @woodgateroberta and David S Busolo} @david_busolo.

Contributors RLW contributed to the conception and design of the study, as well as trained and supervised the hired research assistants who carried out data collection. RLW and DSB performed the data analysis, and drafted, reviewed and approved the manuscript. Both authors agree to be accountable for all aspects of the work.

Funding RLW is supported by a Canadian Institutes of Health Research Applied Chair in Reproductive, Child and Youth Health Services and Policy Research (grant number: CIHR APR-126339). This research was supported by a Canadian Institutes of Health Research (grant number: CIHR MOP84398) operating grant.

Competing interests None declared.

Ethics approval Ethical approval was granted by the Education and Nursing Research Ethics Board at the University of Manitoba.

Provenance and peer review Not commissioned; externally peer reviewed.

Data sharing statement No additional data are available.

Open Access This is an Open Access article distributed in accordance with the Creative Commons Attribution Non Commercial (CC BY-NC 4.0) license, which permits others to distribute, remix, adapt, build upon this work noncommercially, and license their derivative works on different terms, provided the original work is properly cited and the use is non-commercial. See: http:// creativecommons.org/licenses/by-nc/4.0/

\section{REFERENCES}

1. Casarett D, Pickard A, Fishman JM, et al. Can metaphors and analogies improve communication with seriously ill patients? J Palliat Med 2010;13:255-60.
2. Metaphor. Springfield, MA: Merriam-Webster, Incorporated, 2014 [780]. http://www.merriam-webster.com/dictionary/metaphor

3. Harrow A, Wells M, Humphris G, et al. "Seeing is believing, and believing is seeing": an exploration of the meaning and impact of women's mental images of their breast cancer and their potential origins. Patient Educ Couns 2008;73:339-46.

4. Gibbs RW, Franks H. Embodied metaphor in women's narratives about their experiences with cancer. Health Commun 2002;14:139-65.

5. Czechmeister CA. Metaphor in illness and nursing: a two-edged sword. A discussion of the social use of metaphor in everyday language, and implications of nursing and nursing education. $J$ Adv Nurs 1994;19:1226-33.

6. Lyddon WJ, Clay AL, Sparks CL. Metaphor and change in counseling. J Couns Dev 2001;79:269-74.

7. McKeon RPE. The basic works of Aristotle. New York: Random House, 1941.

8. Skott C. Expressive metaphors in cancer narratives. Cancer Nurs 2002;25:230-5.

9. Sontag SJ. Illness as a metaphor. New York, NY: Farrar, Straus and Giroux, 1978.

10. Camus JTW. Metaphors of cancer in scientific popularization articles in the British press. Discourse Stud 2009;11:465-95.

11. Lerner. The breast cancer wars: hope, fear, and the pursuit of a cure in twentieth-century America. Oxford, NY: Oxford University Press, 2001.

12. Penson RT, Schapira L, Daniels KJ, et al. Cancer as metaphor. Oncologist 2004;9:708-16.

13. Jasen P. From the "silent killer" to the "whispering disease": ovarian cancer and the uses of metaphor. Med Hist 2009;53:489-512.

14. Harrington KJ. The use of metaphor in discourse about cancer: a review of the literature. Clin J Oncol Nurs 2012;16:408-12.

15. Wiggins NM. Stop using military metaphors for disease. BMJ 2012;345:e4706.

16. Crane-Okada R. A compass for the cancer journey: scientific, spiritual, and practical directives. Oncol Nurs Forum 2007;34:945-55.

17. Childress JF. Practical reasoning in bioethics. Bloomington: Indiana University Press, 1997.

18. Campbell MK. Cancer is a team sport. Clin J Oncol Nurs 2011;15:349-9.

19. Frank A. At the will of the body: reflections on illness. New York, NY Houghton Mifflin Co, 1991.

20. Annas GJ. Reframing the debate on health care reform by replacing our metaphors. N Engl J Med 1995;332:744-7.

21. Van Rijn-van Tongeren G. Metaphors in medical texts. Amsterdam: Rodopi, 1997.

22. Mukherjee S. The emperor of all maladies: a biography of cancer. New York, NY: Simon \& Schuster, 2010.

23. Reisfield GM, Wilson GR. Use of metaphor in the discourse on cancer. J Clin Oncol 2004;22:4024-7.

24. Subbiah V. How watching the movie Zombieland helps treatment of cancer in teenagers. $J$ Cancer Educ 2012;27:188-91.

25. Lanceley A, Clark JM. Cancer in other words? The role of metaphor in emotion disclosure in cancer patients. Br J Psychother 2013;29:182-201.

26. Love B, Crook B, Thompson CM, et al. Exploring psychosocial support online: a content analysis of messages in an adolescent and young adult cancer community. Cyberpsychol Behav Soc Netw 2012;15:555-9.

27. Oakley A, Bendelow G, Barnes $\mathrm{J}$, et al. Health and cancer prevention: knowledge and beliefs of children and young people. BMJ 1995;310:1029-33.

28. Knighting K, Rowa-Dewar N, Malcolm C, et al. Children's understanding of cancer and views on health-related behaviour: a 'draw and write' study. Child Care Health Dev 2011;37:289-99.

29. Mooney-Somers J, Lewis P, Kerridge I. Discursive constructions of youth cancer: findings from creative methods research with healthy young people. J Cancer Surviv 2016;10:427-36.

30. Woodgate RL, Safipour J, Tailor K. Canadian adolescents' perspectives of cancer risk: a qualitative study. Health Promot Int 2015;30:684-94.

31. Hauser DJ, Schwarz N. The war on prevention: bellicose cancer metaphors hurt (some) prevention intentions. Pers Soc Psychol Bull 2015:41:66-77.

32. Haines I. The war on cancer: time for a new terminology. Lancet 2014;383:1883.

33. Creswell JW. Qualitative inquiry \& research design: choosing among five approaches. 2nd edn. Thousand Oaks, CA: Sage Publications, 2007.

34. Harrison B. Seeing health and illness worlds-using visual methodologies in a sociology of health and illness: a methodological review. Sociol Health IIIn 2002;24:856-72. 
35. Strack RW, Magill C, McDonagh K. Engaging youth through photovoice. Health Promot Pract 2004;5:49-58.

36. Boydell KM, Gladstone BM, Volpe T, et al. The production and dissemination of knowledge: a scoping review of arts-based health research. Forum Qual Soc Res 2012;13.

37. Dahan R, Dick R, Moll S, et al. Photovoice Hamilton 2007: manual and resource kit. Hamilton Community Foundation. Ontario. 2007.

38. Berg LB. Qualitative research methods for the social sciences. 6th edn. Boston, MA: Pearson/Allyn and Bacon, 2007.

39. Hoppe MJ, Wells EA, Morrison DM, et al. Using focus groups to discuss sensitive topics with children. Eval Rev 1995;19: $102-14$

40. Carey M. The group effect in focus groups: planning, implementing, and interpreting focus group research. In: Morse J, ed. Critical issues in qualitative research methods. Thousand Oaks, CA: Sage, 1994:225-41.

41. LeCompte M, Schensul J. Designing and conducting ethnographic research. Walnut Creek, CA: Alta Mira Press, 1999.

42. Roper R, Shapira J. Ethnography in nursing research. Thousand Oaks, CA: SAGE, 2000.

43. Lincoln Y, Guba E. Naturalistic inquiry. Beverley Hills, CA: Sage, 1985.

44. Lakoff G. The contemporary theory of metaphor. In: Ortony A, ed. Metaphor and thought. 2nd edn. Cambridge, England: Cambridge University Press, 1993:678.

45. Kyle RG, Forbat L, Hubbard G. Cancer awareness among adolescents in Britain: a cross-sectional study. BMC Public Health 2012;12:580-0.

46. Hubbard G, Macmillan I, Canny A, et al. Cancer symptom awareness and barriers to medical help seeking in Scottish adolescents: a cross-sectional study. BMC Public Health 2014;14:1117.

47. Woodgate RL. A different way of being: adolescents' experiences with cancer. Cancer Nurs 2005;28:8-15

48. Lewis $\mathrm{P}$, Jordens $\mathrm{CF}$, Mooney-Somers $\mathrm{J}$, et al. Growing up with cancer: accommodating the effects of cancer into young people's social lives. J Pediatr Oncol Nurs 2013;30:311-19.

49. Grant JA, Hundley $\mathrm{H}$. Images of the war on cancer in the Associated Press: centering survivors and marginalizing victims. $A C J$ 2009;11:1-16.

50. Hoffner C, Ye J. Young adults' responses to news about sunscreen and skin cancer: the role of framing and social comparison. Health Commun 2009;24:189-98.

51. Stolberg M. Metaphors and images of cancer in early modern Europe. Bull Hist Med 2014:88:48-74.

52. Seale C. Cancer in the news: religious themes in news stories about people with cancer. Health (N Y) 2001;5:425-40.

53. Jim HSL, Pustejovsky JE, Park CL, et al. Religion, spirituality, and physical health in cancer patients: a meta-analysis. Cancer 2015; $121: 3760-8$

54. Lawton J. Lay experiences of health and illness: past research and future agendas. Sociol Health IIIn 2003;25:23-40.

55. Keeley B, Wright L, Condit CM. Functions of health fatalism: fatalistic talk as face saving, uncertainty management, stress relief and sense making. Sociol Health IIIn 2009;31:734-47.

56. Hanne M, Hawken SJ. Metaphors for illness in contemporary media. Med Humanit 2007;33:93-9.

57. Mosavel M, El-Shaarawi N. "I have never heard that one": young girls' knowledge and perception of cervical cancer. $J$ Health Commun 2007;12:707-19. 